\title{
MADS Box Transcript Amount Is Affected by Ethylene during Abscission
}

\author{
Valeriano Dal Cin*, Angelo Ramina \\ Department of Environmental Agronomy and Crop Science, University of Padua, Padua, Italy. \\ Email: *Valeriano_dalcin@yahoo.com, angelo.ramina@unipd.it
}

Received January $16^{\text {th }}, 2011$; revised March $23^{\text {rd }}, 2011$; accepted March $30^{\text {th }}, 2011$.

\begin{abstract}
Thinning of young fruit is an important agronomical practice to ensure the maximum economic production. This practice is based on the control of the natural self thinning process occurring during fruit development. At the early stages of fruit development (fruitlet), the vegetative part of the tree is competing with the reproductive part of the tree and within the fruit clusters the different fruitlets are competing with each other. As a result the least fit organ abscises, Ethylene and auxin play a central role in this event but the role of ethylene is not thoroughly understood because in other systems abscission occurs partly with ethylene independent processes. We have followed the early development of fruitlets and studied the transcription patterns of MADS-box and ethylene related transcripts. Furthermore, we verified that ethylene has an effect on the expression of some ethylene related and MADS box genes. We propose that the ethylene burst during abscission induction is similar to a stage 2 ethylene system and it is related to fruitlet growth by affecting transcript amount of MADS-boxes which modulate seed development and cortex growth.
\end{abstract}

Keywords: Apple, MADS-Box, Ethylene, Fruit, Ripening

\section{Introduction}

Despite technical advances, growing fruit trees is nowadays still a very labour and time consuming activity [1]. The fact that these plants are grown over several years makes agronomic practices performed one year affecting both the same year production and the following year's yield. The case of apple (Malus $\times$ domestica L. Borkh) is a typical example of this situation because the number of fruits in one year affects both quality and biennial bearing $[2,3]$. The fruit load is an issue which has been dealt with for countless years with several approaches. The most important approach has been the fruit thinning performed by hand throughout the first stages of young fruit development (fruitlet) [4]. Nevertheless, the use of bioregulators to increase the natural tendency of the trees to shed surplus fruit has taken over by many growers [5]. In an attempt to further decrease the production costs for the growers, a genetic approach which would exploit natural variation of the germplasm is of primary importance [6]. In order to optimize the discovery of traits interesting for a specific fruit load, which would give the best economic value, the study of the abscission physiology in the different cultivars is a must $[7,8]$.

Abscission is a common self-mechanism the plant adopts to get rid of specific organs [9]. Fruitlet abscission in apple (Malus $\times$ domestica L. Borkh) occurs in a period of competition between reproductive and vegetative parts and among fruitlets [7]. This competition is due to several factors $[8,10,11]$. Hormones play a central role in modulating abscission as can be proven by the fact that bioregulators are widely used to thin excess fruitlet load [5].

The studies performed on this species pointed out that auxin, ethylene and their interaction are of primary importance $[12,13]$. Briefly, it was previously found that a massive increase in MdACO1 transcript amount was concomitant with an increase in elements involved in the signal transduction pathway. Furthermore, the variation in transcript amount followed the increase in ethylene evolution [12]. In Arabidopsis, tomato, rice and several other species these genes are present as multigene families whose members may have specific functions depending on the tissue and/or developmental stage [14]. The situation in apple ripening is similar to the other plants [15]. Nevertheless, neither the involvement of ethylene nor the function of the specific elements during abscission is completely understood.

Ethylene is a hormone with a wide range of functions [16]. In apple abscission induction the increase in ethylene evolution corresponded to a decrease in growth rate 
[8]. During abscission induction (the first weeks after full bloom) the stage of cell division is progressively taken over by cell expansion [17-19]. The flower pollination and the subsequent ovule fertilization bring about deep modification of the ontogenetic program of the organ [20]. It has been found that MADS-box proteins play a crucial role in flower and fruit development [21-25]. Although the main studies on fruit have been performed on tomato, which is a berry, there are reports indicating that the mechanisms are conserved, at least partially, in other fruit such as banana [26], grape berry [27-29], peach [30] cucumber [31] and apple [17,32-35]. MADS-boxes have also been found involved in vegetative processes [36-39] with good conservation of activity $[40,41]$. In this manuscript the role of ethylene during abscission is further investigated. Furthermore, the relationship between ethylene and the level of the transcripts of some MADS box genes is assessed.

\section{Materials and Methods}

\subsection{Plant Material}

Experiments were performed as previously reported on eight-year old apple trees (cv Golden Delicious/M9) Malus $\times$ domestica bearing two fruitlet populations characterized by different abscission potential. These populations which were named abscising fruitlet (AF) and non abscising fruitlet (NAF) were obtained as previously described [42]. Apple trees display a natural tendency to shed lateral fruitlets while maintaining central ones. Nevertheless, this phenomena is amply variable and in order to maximize and homogenize the starting material the abscising fruitlet population (AF) was obtained from lateral fruitlets born on trees sprayed with benzylaminopurine (BA). The product was applied at $200 \mathrm{ppm}$ (commercial form "Brancher-Dirado") when the average fruit diameter was $10-12 \mathrm{~mm}(17 \mathrm{~d}$ after petals fall, APF). In this period abscission induction of the shedding process occurs [43] It is in this time window that abscission which can be stimulated by thinners with the greatest efficiency [4,5]. A population with almost non abscission, named non-abscising fruitlets (NAF), was generated by removing all the laterals from the cluster at petal fall and leaving, exclusively, the central flower freely pollinated at bloom with compatible pollen (cv. Stark Red). Seed, cortex, peduncle (the central $15 \mathrm{~mm}$ ) and abscission zone (AZ) of each population were collected from fruitlets at 0 , $3,5,7$ days after $\mathrm{BA}$ was applied to the $\mathrm{AF}$, frozen in liquid nitrogen, and stored at $-80^{\circ} \mathrm{C}$ for molecular analysis. Fruitlet diameter was measured with a caliber and statistical analysis was performed with a 2 way ANOVA of the GRAPH PAD PRISM software. Parameters studied were population, time and time/population interaction. Threshold was $5 \%$.

\subsection{Ethylene Experiment}

For the ethylene experiment, entire apple fruitlet clusters at $15 \mathrm{DAPF}$ were treated with propylene $\left(1000 \mu \mathrm{L} \cdot \mathrm{L}^{-1}\right)$ or 1-MCP $\left(1 \mu \mathrm{L} \cdot \mathrm{L}^{-1}\right)$ or left untreated (control) as described in [44]. At the end of the treatment fruitlet clusters were retrieved and divided into central and lateral. Tissues (abscission zone, peduncle, cortex and seed) were collected at the beginning of the experiment (T0) and after 24 hours for molecular analysis.

\subsection{Molecular Biology Studies}

RNA extraction and expression analyses were as previously described $[45,46]$. Degenerative primers (Table 1) were designed as previously described [47]. The expression analysis was repeated at different number of cycles but to make the results easily understandable and comparable both between the two different populations: NAF and $\mathrm{AF}$ and among organs (seed, cortex, peduncle and $\mathrm{AZ}$ ) only significant differences were presented and commented (Tables 2 and 3). Primers for expression analyses

Table 1. Degenerate primer sequences.

\begin{tabular}{ccclr}
\hline gene & ACCN & Dir & \multicolumn{1}{c}{ seq } & T \\
\hline \multirow{2}{*}{ ETR55 } & DQ & F & CAAGARGTTGGGWTGATGAAG & 50 \\
& 84545860 & R & ACTKGCCATCATHGCATTCT & \\
CTR2 & DQ & F & GGMATGGMWCWGAKGTTGCTGT & 55 \\
& 845459 & R & CAAATCACGTGGAATCTCAAG & \\
EIN2 & DQ & F & ATCSCTKTGGKCYARRCARCC & 55 \\
EIN2 & DQ & F & CTTTATGAAGCTGAAACTAGAGAGAT 68 \\
3p & 845461 & R & AYKCCCTGWAGRCGRTTGAGA & \\
\hline
\end{tabular}

The gene name, the accession number (ACCN), the sequences (seq) of the primer forward (F) and reverse (R) (dir) 5's $\rightarrow 3$ ' as well as the temperature in ${ }^{\circ} \mathrm{C}$ used in the annealing step of the amplification are presented.

Table 2. Primer sequences for ethylene specific genes.

\begin{tabular}{cccl}
\hline gene & ACCN & Dir & \multicolumn{1}{c}{ Primer F } \\
\hline \multirow{2}{*}{ ACO2 } & DQ439790 & F & CGGCACCTTCCTTCCTCA \\
& & R & GATGACAATGGAGTGGTGCA \\
ACO4 & CN907149 & F & CTTGATGCCGTTCAGACAGA \\
& & R & CCAAGATTCTCACACAACAAGC \\
ETR5 & DQ845458 & F & GTTCTTCCGGTTGCAGAT \\
& & R & AGCCAGTTTCTCCCTCATTA \\
EIN2 & DQ845461 & F & GCTACAAGCGTAGATTATCC \\
& & R & CAGAAGATGAGCTGTTTCC \\
CTR2 & DQ845459 & F & TACACGTCCTCCAAACCT \\
& & R & ACAATCGTCGGTGTACTG \\
UBI & DQ438989 & F & CATCCCCCAGACCAGCAGA \\
& & R & ACCACGGAGACGCAACACCAA \\
rib 18s & & F & GTTACTTTTAGGACTCCGCC \\
& & R & TTCCTTTAAGTTTCAGCCTTG \\
\hline
\end{tabular}

The gene name, the accession number (ACCN), the sequences (seq) of the primer forward $(\mathrm{F})$ and reverse (R) (dir) 5 's $\rightarrow 3$ ' used in the amplification are presented. 
Table 3. primer sequences for MADS box specific genes.

\begin{tabular}{cccl}
\hline GENE & ACCN & D & \multicolumn{1}{c}{ seq } \\
\hline \multirow{2}{*}{ MADS5 } & \multirow{2}{*}{ ABG85297 } & F & TTGAGTACGCCACAGATTCAT \\
& & R & ATTCAAAGGTCCAGTTACCC \\
MADS7 & CAA04323 & F & CCCTCATCTTTTTATCC \\
& & R & GGTTAAGATCAGAGGTAGACA \\
MADS9 & CAA04920 & F & TGGCAATATATAAACTGCATG \\
& & R & AGCAAGAAATAAGTCGCAA \\
MADS10 & CAA04324 & F & GTACAAGGCATGTTCAGAT \\
& & R & GCTTCTCCACCCTCGATCA \\
MADS11 & CAA04325 & F & GGTATGAGCAAAACCCTTGA \\
& & R & GATCTTCACCAAGCAAATGC \\
MADS12 & CAC86183 & F & AGCAGTGGATGACAATGATTC \\
& & R & TCAAATGGCGAAAGCATC \\
MADS14 CAC80857 & F & GCAGCAGCAAACACATATGAT \\
& & R & ATTGGACTCCAAGATCACAG \\
MADS15 & CAC80858 & F & CCACGATCAGATTTCTCTTCA \\
& & R & GACAAGAAATCCCCTTCCAT \\
PIST & AJ291491 & F & GGCACTGGAAGATGAGAATAA \\
& & R & AAGGCAAAAGGTATCTGCTG \\
\hline
\end{tabular}

The gene name, the accession number (ACCN), the sequence (seq) of the primers 5 ' $\rightarrow 3$ ' and their direction $\mathrm{D}$ ( $\mathrm{F}$ is forward and $\mathrm{R}$ is reverse) used in the amplification are presented. were designed with the Gene fisher program http://bibiserv.techfak.uni-bielefeld.de/genefisher2/ [48] Similarity research was performed at the ncbi website http://blast. ncbi.nlm.nih.gov/Blast.cgi with the blastp algorithm [49]. Phylogenetic analysis was performed with th MEGA4 program [50].

\section{Results}

\subsection{Isolation of Ethylene Related Transcripts}

The fragments isolated in this study encode for an ETR5, a CTR2 and an EIN2. MdETR5 is 663bp (DQ845460) and encodes a fragment of $211 \mathrm{aa}$. The blast analysis indicated a high level of similarity to proteins from several species, among which an ETR5 from Malus and Pyrus, and Neverripe and ETR4 from tomato (Table 4). MdCTR2 (DQ845459) is 614bp and encodes a fragment of 193 aa. The bioinformatic analysis indicated close similarity to EDR1 of Arabidopsis thaliana and TCTR2 of tomato (Table 5). MdEIN2 (DQ845461) is 1158bp long and encodes for a partial protein of 302aa, which is highly similar to EIN2 of Arabidopsis and Petunia (Table 6).

Table 4. Level of similarity between MdETR5 isolated in this study and other elements present in the database.

\begin{tabular}{|c|c|c|c|}
\hline Annotation & ACCNN. & identity & E-value \\
\hline ethylene receptor 5 [Malus $\times$ domestica] & ABI58287 & $99 \%$ & $5 e-101$ \\
\hline putative ethylene receptor [Pyrus communis] & AAL66193 & $98 \%$ & $1 e-99$ \\
\hline unnamed protein product [Vitis vinifera] & $\mathrm{CAO} 65024$ & $80 \%$ & $6 e-78$ \\
\hline ethylene receptor [Persea americana] & ABY76321 & $75 \%$ & $9 e-72$ \\
\hline hypothetical protein [Vitis vinifera] & CAN66907 & $77 \%$ & $2 \mathrm{e}-71$ \\
\hline ethylene receptor neverripe [Lycopersicon esculentum]. & AAU34077 & $72 \%$ & $4 \mathrm{e}-70$ \\
\hline ethylene receptor homolog (ETR4) & AAD31396 & $70 \%$ & $3 e-68$ \\
\hline
\end{tabular}

The annotation retrieved by similarity search, the accession number (ACCN), identity and E-values are reported.

Table 5. Level of similarity between MdCTR2 isolated in this study and other elements present in the database.

\begin{tabular}{|c|c|c|c|}
\hline Annotation & Acc. $\mathrm{N}$ & identity & E-value \\
\hline CTR2 protein kinase [Rosa hybrid cultivar] & AAK30005 & $94 \%$ & $3 e-110$ \\
\hline unnamed protein product [Vitis vinifera] & CAO42985 & $93 \%$ & $5 e-109$ \\
\hline mitogen-activated protein kinase [Medicago sativa] & ABD76389 & $92 \%$ & $3 e-107$ \\
\hline enhanced disease resistance 1 [Arabidopsis thaliana] & ABR45968 & $88 \%$ & $2 \mathrm{e}-103$ \\
\hline enhanced disease resistance 1 [Arabidopsis lyrata] & ABR45984 & $88 \%$ & $2 \mathrm{e}-103$ \\
\hline TCTR2 protein [Solanum lycopersicum] & CAA06334 & $88 \%$ & $2 \mathrm{e}-103$ \\
\hline hypothetical protein OsJ 009144 [Oryza sativa (japonica cultivar-group)] & EAZ25661 & $86 \%$ & $6 \mathrm{e}-102$ \\
\hline
\end{tabular}

The annotation retrieved by similarity search, the accession number (ACCN), identity and E-values are reported. 
Table 6. Level of similarity between MdEIN2 isolated in this study and other elements present in the database.

\begin{tabular}{lccc}
\hline \multicolumn{1}{c}{ Annotation } & Acc. N & identity & E-value \\
\hline ethylene signaling protein [Prunus persica] & ABC94581 & $85 \%$ & $2 \mathrm{e}-146$ \\
hypothetical protein [Vitis vinifera] & CAN66374 & $72 \%$ & $2 \mathrm{e}-121$ \\
EIN2 (ETHYLENE INSENSITIVE 2); transporter [Arabidopsis thaliana] & NP_195948 & $69 \%$ & $4 \mathrm{e}-117$ \\
EIN2 [Petunia $\times$ hybrida] & AAR08678 & $71 \%$ & $1 \mathrm{e}-114$ \\
sickle [Medicago truncatula] & ACD84889 & $68 \%$ & $4 \mathrm{e}-112$ \\
ethylene-insensitive 2 [Lycopersicon esculentum] & AAZ95507 & $71 \%$ & $3 \mathrm{e}-111$ \\
ethylene insensitive 2 [Zea mays] & AAR25570 & $55 \%$ & $4 \mathrm{e}-78$ \\
\hline
\end{tabular}

The annotation retrieved by similarity search, the accession number (ACCN), identity and E-values are reported.

\subsection{Expression of Ethylene Related Genes during Abscission}

The overall results indicate the genes MdACO2, MdETR5 and MdCTR2 are expressed in all the tissues at similar level; whereas MdACO4 and MdEIN2 are mainly expressed in peduncle and AZ (Figure 1). MdACO4 transcripts in seed decreased in both AF and NAF although in NAF the decline was less severe. In cortex the expression was constant in AF whereas it peaked in NAF at day 3 then plunged. In peduncle expression was constant in AF whereas it declined in NAF. In AZ expression remained constant. MdETR5 expression in seed first increased in both AF and NAF then declined but in NAF the decline was less pronounced. In cortex expression was constant in AF whereas a decline was monitored in NAF. In peduncle transcripts increased in both populations then decreased in NAF while remaining constant in AF. In AZ expression was high and constant in both AF and NAF. MdEIN2 transcript level in seed paralled the one of MdETR5. In cortex the expression was at its lowest and further declined in both AF and NAF. In peduncle and $\mathrm{AZ}$ expression did not vary. MdCTR2 transcript level was constant in AF whereas it decreased in NAF. In cortex expression slightly increased in AF whereas it steadily declined in NAF. In peduncle and AZ transcript level did not change.

\subsection{Fruitlet Growth}

It was previously found that fruitlet diameter increased even in the days preceding abscission [8]. In this study we confirmed this discovery and found that fruitlet diameters significantly increased in both populations but in NAF the increase was more pronounced than in AF (Figure 2).

\subsection{Bioinformatic Analysis of the MADS-Box in Malus $\times$ domestica}

The databases present in the world wide web were searched for MADS-box genes of different species: Arabidopsis thaliana, Solanum lycopersicum, Populus tremula and Malus domestica. The results obtained by the blast $\mathrm{P}$ algorithm (data not shown) and by the phylogenetic analysis were similar (Figure 3). The sequences of apple

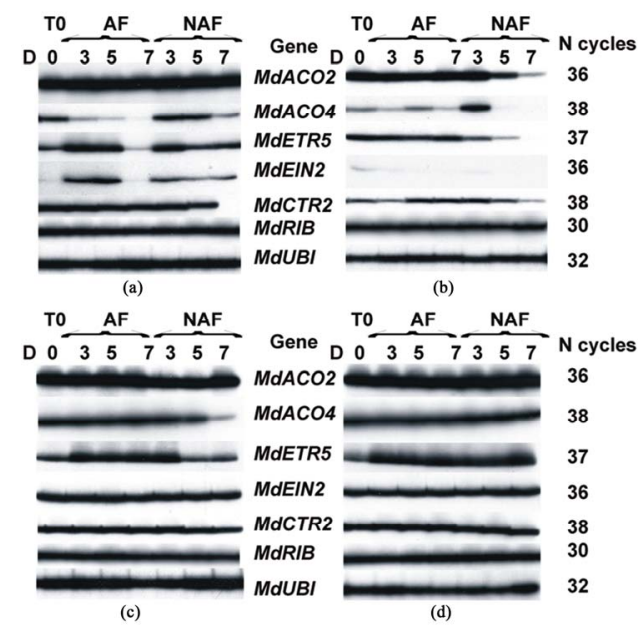

Expression analysis on the two populations studied: abscising fruitlets (AF) and non abscising fruitlets (NAF) at different days: 3,5 and 7 . T0 means the beginning of the experiment. Tissue Fruitlet parts are: seed (a), cortex (b), peduncle (c) and AZ (d) of different genes. The number of cycles (N cycles) is reported.

Figure 1. Expression analysis of genes involved in ethylene.

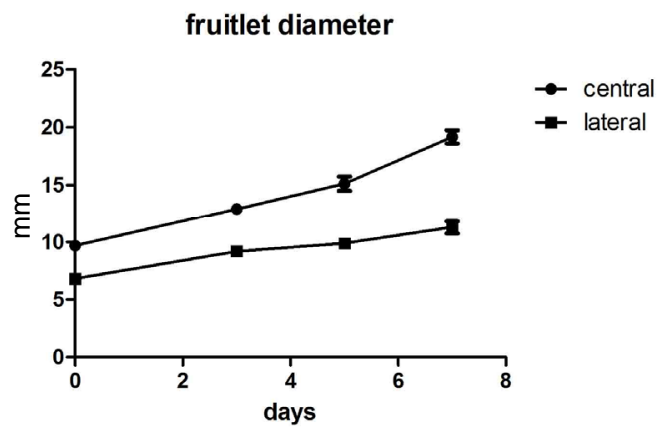

Fruitlet diameter of the cortex fruitlets expressed in $\mathrm{mm}$. Cortex diameter of lateral fruitlets from $\mathrm{AF}$ is represented as square. Cortex diameter of fruitlets from NAF is presented as circles. Bars represent SE.

Figure 2. Fruitlet diameter. 


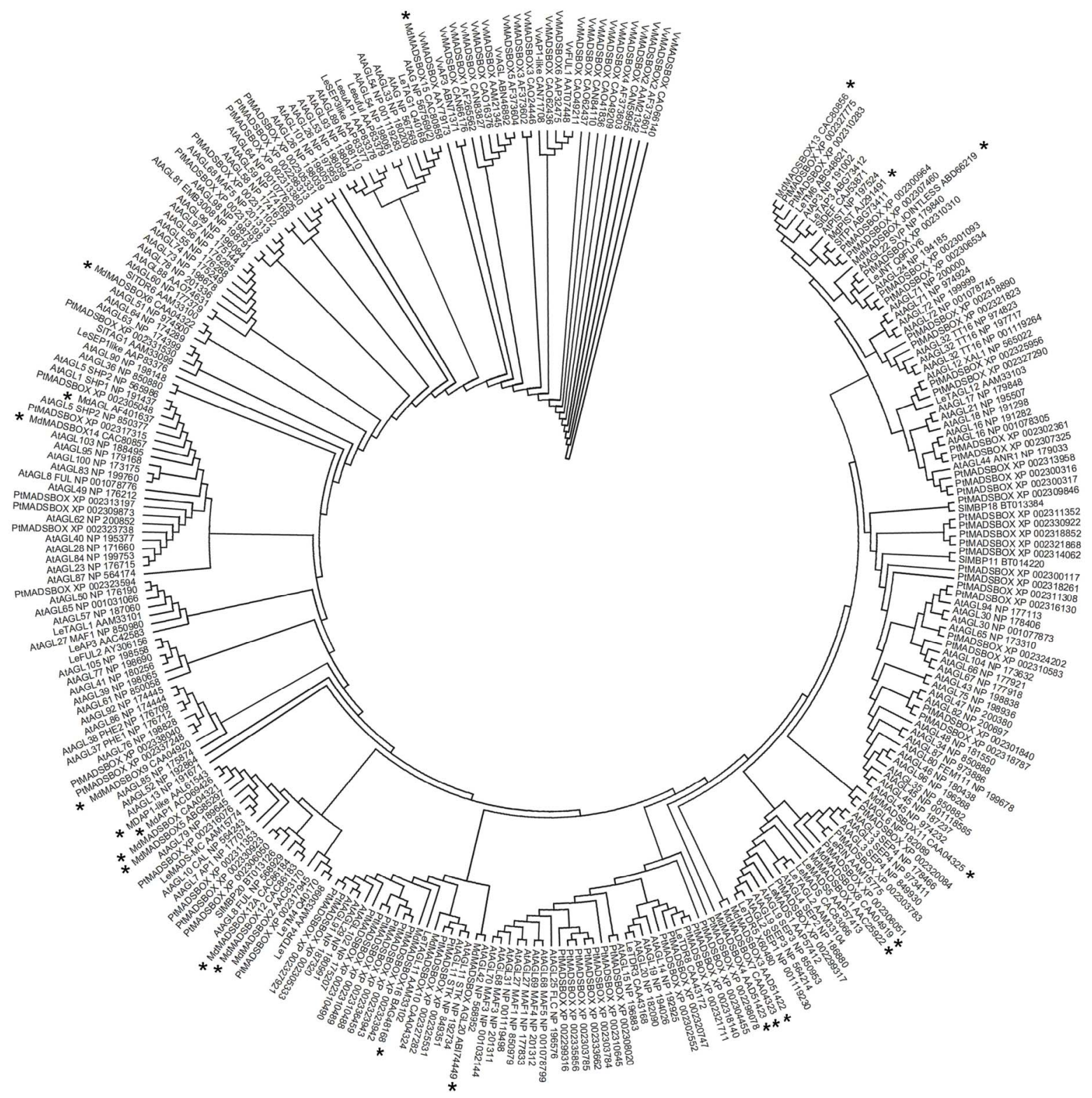

MADS-box genes of different species: Arabidopsis thaliana (At), Solanum lycopersicum (S1), Populus tremula (Pt) and Malus domestica (Md). Similar MADS box proteins are grouped together. The stars indicate the apple MADS box proteins. The accession number follows the name of the proteins.

Figure 3. Phylogenetic study of the MADS box proteins known and previously studied in apple.

already known are widespread among the several MADS-box clades [51,52]. The genes we found expressed clustered in the groups with previously identified genes with known phenotypes. Nevertheless, there was not clear horthologos. MADS5 resemble MC of tomato and CAL of Arabidopsis [53]. MADS7 resembles the tomato RIN and other Arabidopsis SEP genes [53]. MADS9 is in the SEP group and is similar to PHE of Arabidopsis. MADS10 is an AGL probably seedstick (STK) [54]. MADS11 is another AGL similar to TDR3 and 8 of tomato. MADS12 clusters with fruitful (FUL) [55]. MADS14 is an AGL similar to shatterproof (SHP1) [56]. MADS15 is an agamous in Arabidopsis (AG) and tomato (TAG1). PIST is a pistillata gene [57] and JNT is similar to tomato jointless [58] (Figure 3).

\subsection{Expression of MADS Box Genes during Abscission}

The overall expression analysis indicated that the most expressed genes were MADS5 and MADS10 in terms of 
number of cycles used during analysis and intensity of the signal. Furthermore, the tissues displaying the main changes along abscission were the seed and the cortex (Figure 4). MADS5 transcripts were at a steady state in peduncle and AZ whereas the amount increased in NAF seed and decreased in AF cortex. MADS7 expression was specific of seed where it declined along the experiment in both populations but an abrupt increased was detected at day 7 in AF. MADS9 expression in seed declined along the experiment but in NAF it was delayed. In cortex expression increased in NAF. In peduncle and $\mathrm{AZ}$ expression was at a higher level than seed and cortex and unchanged along the experiment. MADS10 transcript level in seed decreased in AF while it remained unchanged in NAF. In cortex expression steadily declined in AF whereas it was a sudden in NAF. Similar situation was observed in peduncle. In AZ the expression was limited to NAF at day 3. MADS11 expression in seed decreased in AF whereas it remained constant in NAF. In cortex expression declined along the experiment in AF more gradually than in NAF. In peduncle transcript level remained at a steady level in AF whereas it declined in NAF. In AZ expression increased in both AF and NAF although earlier in the latter. MADS12 transcripts were detected only in seed at day 7. MADS14 expression was unchanged in seed and peduncle whereas in cortex a decrease was observed along the experiment more suddenly in NAF. In the AZ of AF the level suddenly decreased at day 7. MADS15 expression in seed declined along experiment mainly in AF. In cortex expression declined along experiment, more abruptly in NAF. No variation was observed in peduncle and AZ. MdPIST was detected only in seed of the NAF at day 3 and 7 and in peduncle of the NAF at day 7. Transcripts of JMD were detected only in peduncle and $\mathrm{AZ}$ and no difference or variation was observed (data not shown).

\subsection{Ethylene Effect on Transcripts}

The treatments with propylene and $1 \mathrm{MCP}$ indicated that $M d A C O 2$ is negatively affected by ethylene, whereas $M d-$ ERS1, MdETR5, MdCTR2 and to some extent MdEIN2 expression is positively regulated by ethylene. Of all the MADS investigated, only MADS9 (in cortex) and MADS10 (in seed) showed to respond to the treatments, being both negatively regulated by ethylene (Figure 5 ).

\section{Discussion}

The genes isolated in this study encode for elements involved in ethylene perception and transduction [14]. Previous research showed that in apple like in other plants ethylene receptors are encoded by a multigene family [12] and MdETR5 is likely to be the same gene previously isolated [15]. MdCTR2 represents a new element isolated in this species. It has been shown that CTR2 is similar to other CTR1 elements in both Arabidopsis [59] and tomato [60]. It has also been proposed that the member present in Arabidopsis is likely to be involved in defense mechanisms [61]. The data here presented indicate that CTR2 in apple may have a general role in ethylene signal transduction during apple development. Likewise, it has been demonstrated in tomato that this element may have

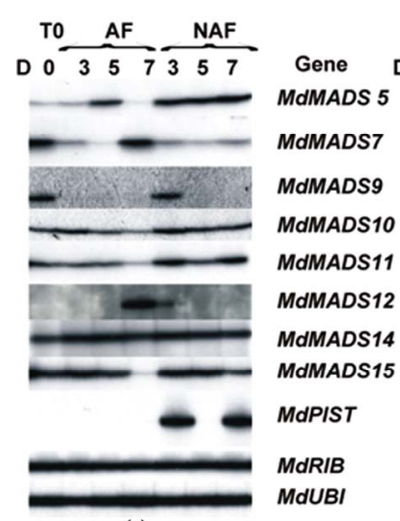

(a)

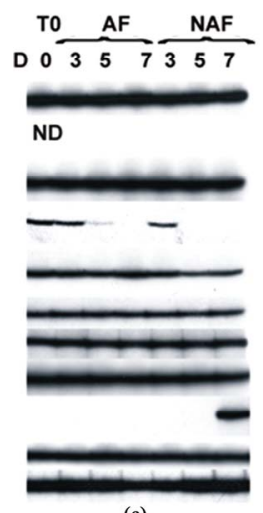

(c)

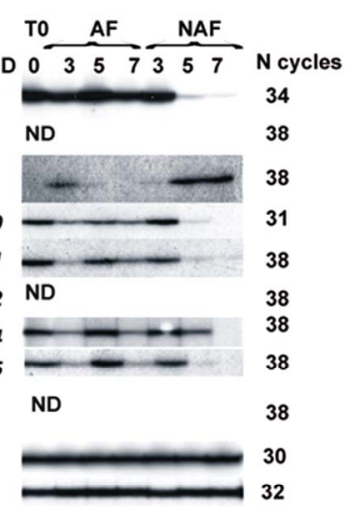

(b)
Expression analysis on the two populations studied: abscising fruitlets (AF) and non abscising fruitlets (NAF) at different days: 3, 5 and 7. T0 means the beginning of the experiment. Tissues Fruitlet parts are: seed (a), cortex (b), peduncle (c) and AZ (d) of different genes. The number of cycles ( $\mathrm{N}$ cycles) is reported.

Figure 4. Expression analysis of MADS box genes.

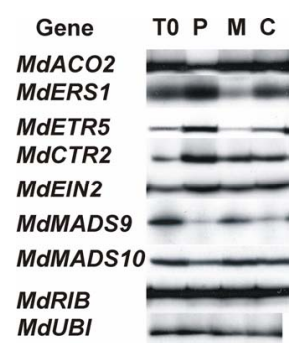

Expression analysis of the genes affected by propylene (P) or 1-MCP (M). The control $(\mathrm{C})$ and the samples at the beginning (T0) of the experiment are also presented. Apart from MADS box 10 (MADS10, studied in seed) all the other expression analysis are from the cortex tissue.

Figure 5. Expression analysis of genes affected by ethylene. 
a wider involvement [62] (Lin et al., 2008). The EIN2 in this study is almost identical to the one previously isolated [15] and the expression pattern of this gene and of the others genes involved in ethylene biology indicate that the hormone may be involved in mechanisms of development [63], cell differentiation and programmed cell death like in maize kernel [64]. Nonetheless, these elements have not been previously studied during abscission induction. As previously found [12] the organs in which the changes are most evident during abscission induction are the seed and the cortex. Analogously to previous findings, the peduncle also showed late variation in MdETR5 transcript amount. These results confirm that seed and cortex are likely to control the changes in ethylene biosynthesis and transduction previously described [12]. The results throughout abscission and in the ethylene experiment suggest that MdACO2, MdETR5 and MdCTR2 are either directly or secondarily controlled by ethylene. It has been suggested that in apple, ethylene could affect fruit development in the late stages of fruit maturation [65]. Immature apple abscission occurs during the first stages of fruit development in which cell division leads the way to fruitlet growth by cell enlargement [17]. Ethylene is not to be considered related to the processes occurring immediately after ovule fertilization [20] because 2 weeks after pollination seeds are already in advanced development. It has been found that ethylene is present at basal level in NAF whereas an increase is present in AF [12]. Ethylene at this stage may have a broad importance in development of the different tissues [16]. The expression pattern in seed of MdERS1, MdETR5 and MdEIN2; higher in NAF than AF followed by a sudden decrease may be seen as a delay in development and a total block by day 7 . This hypothesis is supported by the drop in both MdAHS and MdPIN1 transcripts previously reported $[10,13]$ and recently revisited in [66]. MdCTR2 transcript level on the other hand may be mainly related to the transduction of the high ethylene level during the first stages of abscission induction $[12,8]$. This situation may be compared to a system II-like ethylene production where increases in ethylene determine a positive feedback as previously reported in citrus [67]. The effect of ethylene on fruitlet growth and development previously suggested [8] and here confirmed is likely connected to auxin [13]. The results of the MADSBOX transcripts indicate these genes are in general expressed in both reproductive and vegetative parts but could be recruited for different functions as previously found [36]. Nevertheless, there are some specific domains for MdMADS7 and MdPIST in seed and MdMADS12 in peduncle and AZ. The results concerning MdMADS12 in seed were obtained by overexposure of the films and its physiological relevance outside the organs where the horthologs are generally expressed, cannot be inferred without excessive speculation. Our study was not meant to elucidate whether the MADS box isolated in apple have exactly the same physiological function of the genes closely similar in other species. Indeed, as previously found in banana [26] the horthologous genes may not have completely conserved function across species. This statement is especially valid for MADS box with a SEP motif [68]. On the other hand, the function of MADS box proteins with the AG and PIST motives are more conserved across species probably because they have undergone a limited number of duplication [69]. The fact that MdPIST transcripts were found only in seed at day 3, at day 7 transcripts were detected only by overexposure of the film, and the expression analysis in published literature [57] indicate a specific action of MdPIST during normal ovule development. MdPIST expression may be a result of a signal activating specific changes during ovule development. The results here presented also indicate that throughout abscission induction there are variations in the transcript amount of MADS-box genes: especially MdMADS5. MdMADS9, MdMADS10, MADS15 and MdPIST. The low transcript amount of MdMADS10 and MdPIST in AF seeds compared to NAF seeds are likely due to a total block or reduced development of the ovule and are the most interesting findings. The decrease or absence of these proteins may reduce development and make the fruitlet sensitive to competition with other fruitlets and with the vegetative part of the plant leading to abscission. Another possibility is that these genes are just related to senescence processes occurring during abscission. A further interesting possibility is that the downregulation of some MADS-box may actually lead to abscission as verified in tomato [70] and that ethylene affects seed development besides other processes such as auxin production and transport and senescence $[10,13]$.

\section{REFERENCES}

[1] L. Calvin and P. Martin, "The US Produce Industry and Labor: Facingthe Future in a Global Economy," Economic Research Report No. (ERR-106), November 2010, p. 106.

[2] H. Link, "Significance of Flower and Fruit Thinning on Fruit Quality," Plant Growth Regulation, Vol. 31, No. 1-2, 2000, pp. 17-26. doi:10.1023/A:1006334110068

[3] V. Dal Cin, M. Danesin, A. Botton, A. Boschetti, A. Dorigoni and A. Ramina, "Fruit Load and Elevation Affect Ethylene Biosynthesis and Action in Apple Fruit (Malus domestica L. Borkh) during Development, Maturation and Ripening," Plant Cell and Environment, Vol. 30, No. 11, 2007, pp. 1480-1485. doi:10.1111/j.1365-3040.2007.01723.x

[4] K. M. Jones, S. A. Bound, M. J. Oakford and P. Gillard, "Modelling Thinning of Pome Fruits," Plant Growth 
Regulation, Vol. 31, No. 1-2, 2000, pp. 75-84. doi:10.1023/A:1006315000499

[5] S. J. Wertheim, "Developments in the Chemical Thinning of Apple and Pear," Plant Growth Regulation, Vol. 31, No. 1-2, 2000, pp. 85-100. doi:10.1023/A:1006383504133

[6] L. Sun, M. John Bukovac, P. Forsline and S. van Nocker, "Natural Variation in Fruit Abscission-Related Traits in Apple (Malus domestica)," Euphytica, Vol. 165, No. 1, 2009, pp. 55-67. doi:10.1007/s10681-008-9754-x

[7] F. Bangerth, "Abscission and Thinning of Young Fruit and Their Regulation by Plant Hormones and Bioregulators," Plant Growth Regulation, Vol. 31, No. 1, 2000, pp. 43-59.

[8] V. Dal Cin, A. Boschetti, A. Dorigoni and A. Ramina, "Benzylaminopurine Application on Two Different Apple Cultivars (Malus domestica L. Borkh) Displays New and Unexpected Fruitlet Abscission Features," Annals of Botany, Vol. 99, No. 6, 2007, 1195-1202. doi:10.1093/aob/mcm062

[9] J. Taylor and C. Whitelaw, "Signals in Abscission," New Phytologist, Vol. 151, No. 2, 2001, pp. 323-339. doi:10.1046/j.0028-646x.2001.00194.x

[10] V. Dal Cin, E. Barbaro, M. Danesin, H. Murayama, R Velasco and A. Ramina, "Fruitlet Abscission: A cDNA AFLP Approach to Study Genes Differentially Expressed during Shedding of Immature Fruits Reveals the Involvement of a Putative Auxin Hydrogen Symporter in Apple (Malus domestica L. Borkh)," Gene, Vol. 442, No. 1-2, 2009, pp. 26-36.

[11] C. Zhou, A. Lakso, T. Robinson and S. Gan, "Isolation and Characterization of Genes Associated with ShadeInduced Apple Abscission," Molecular Genetics and Genomics, Vol. 280, No. 1, 2008, pp. 83-92. doi:10.1007/s00438-008-0348-z

[12] V. Dal Cin, M. Danesin, A. Boschetti, A. Dorigoni and A. Ramina, "Ethylene Biosynthesis and Perception in Apple Fruitlet Abscission (Malus domestica L. Borkh)," Journal of Experimental Botany, Vol. 56, 2005, No. 421, pp. 2995-3005.

[13] V. Dal Cin, R. Velasco and A. Ramina, "Dominance Induction of Fruitlet Shedding in Malus $\times$ domestica (L. Borkh): Molecular Changes Associated with Polar Auxin Transport," BMC Plant Biology, Vol. 9, 2009, p. 139. doi:10.1186/1471-2229-9-139

[14] C. Chang, "Ethylene Biosynthesis, Perception, and Response," Journal of Plant Growth Regulation, Vol. 26, No. 2, 2007, pp. 89-91. doi:10.1007/s00344-007-9003-X

[15] P. A. Wiersma, H. Zhang, C. Lu, A. Quail and P. M. A. Toivonen, "Survey of the Expression of Genes for Ethylene Synthesis and Perception during Maturation and Ripening of 'Sunrise' and 'Golden Delicious' Apple Fruit," Postharvest Biology and Technology, Vol. 44, No. 3, 2007, pp. 204-211. doi:10.1016/j.postharvbio.2006.12.016

[16] F. B. Abeles, P. W. Morgan and M. E. Saltveit Jr., "Ethylene in Plant Biology," Academic Press, Inc., Cambridge,
1992.

[17] Y. H. Dong, B. J. Janssen, L. B. J. Bieleski, R. G. Atkinson, B. A. M. Morris and R. C. Gardner, "Isolating and Characterizing Genes Differentially Expressed Early in Apple Fruit Development," Journal of the American Society for Horticultural Sciences, Vol. 122, No. 6, 1997, pp. 752-756.

[18] C. Pratt, "Apple Flower and Fruit: Morphology and Anatomy," Horticultural Reviews, Vol. 10, 1988, pp. 273-280. doi:10.1002/9781118060834.ch8

[19] P. Boonkorkaew, S. Hikosaka and N. Sugiyama, "Effect of Pollination on Cell Division, Cell Enlargement, and Endogenous Hormones in Fruit Development in a Gynoecious Cucumber," Scientia Horticulturae, Vol. 116, No. 1, 2008, pp. 1-7. doi:10.1016/j.scienta.2007.10.027

[20] Y. H. Dong, A. Kvarnheden, J.-L. Yao, P. W. Sutherland, R. G. Atkinson, B. A. Morris and R. C. Gardner, "Identification of Pollination-Induced Genes from the Ovary of Apple (Malus domestica)," Sexual Plant Reproduction, Vol. 11, No. 5, 1998, pp. 277-283. doi:10.1007/s004970050154

[21] J. J. Giovannoni, "Molecular Biology of Fruit Maturation and Ripening," Annual Review of Plant Physiology \& Plant Molecular Biology, Vol. 52, 2001, pp. 725-749. doi:10.1146/annurev.arplant.52.1.725

[22] J. J. Giovannoni, "Genetic Regulation of Fruit Development and Ripening," The Plant Cell, Vol. 16, 2004, pp. S170-S180. doi: $10.1105 /$ tpc. 019158

[23] J. J. Giovannoni, "Fruit Ripening Mutants Yield Insights into Ripening Control," Current Opinion in Plant Biology, Vol. 10, No. 3, 2007, pp. 283-289. doi:10.1016/j.pbi.2007.04.008

[24] H. Sommer, J. Beltran, P. Huijser, H. Pape, W. Lonnig, H. Saedler and Z. Schwarz-Sommer, "Deficiens, a Homeotic Gene Involved in the Control of Flower Morphogenesis in Antirrhinum majus: The Protein Shows Homology to Transcription Factors," The EMBO Journal, Vol. 9, No. 3, 1990, pp. 605-613.

[25] E. Coen and E. Meyerowitz, "The War of the Whorls: Genetic Interactions Controlling Flower Development," Nature, Vol. 353, 1991, pp. 31-37.

[26] T. Elitzur, J. Vrebalov, J. J. Giovannoni, E. E. Goldschmidt, and H. Friedman, "The Regulation of MADS-Box Gene Expression during Ripening of Banana and Their Regulatory Interaction with Ethylene," Journal of Experimental Botany, Vol. 61, No. 5, 2010, pp. 1523-1535. doi:10.1093/jxb/erq017

[27] L. Fernandez, L. Torregrosa, N. Terrier L. Sreekantan, J. Grimplet, D. Davies, M. R. Thomas, C. Romieu and A. Ageorges, "Identification of Genes Associated with Flesh Morphogenesis during Grapevine Fruit Development," Plant Molecular Biology, Vol. 63, No. 3, 2007, pp. 307-323. doi:10.1007/s11103-006-9090-2

[28] J. Diaz-Riquelme, D. Lijavetzky, J. M. Martinez-Zapater and M. J. Carmona, "Genome-Wide Analysis of MIKC C Type MADS Box Genes in Grapevine," Plant Physiology, Vol. 149, No. 1, 2009, pp. 354-369. 
doi:10.1104/pp.108.131052

[29] M. J. Poupin, F. Federici, C. Medina, J. T. Matus, T. Timmermann and P. Arce-Johnson, "Isolation of the Three Grape Sub-Lineages of B-Class MADS-Box TM6, PISTILLATA and APETALA3 Genes Which Are Differentially Expressed during Flower and Fruit Development," Gene, Vol. 404, No. 1-2, 2007, pp. 10-24.

[30] Y. Xu, L. Zhang, H. Xie, Y.-Q. Zhang, M. Oliveira and R.-C. Ma, "Expression Analysis and Genetic Mapping of Three SEPALLATA-Like Genes from Peach (Prunus persica (L.) Batsch)," Tree Genetics \& Genomes, Vol. 4, No. 4, 2008, pp. 693-703. doi:10.1007/s11295-008-0143-3

[31] M. K. Filipecki, H. Sommer and S. Malepszy, "The MADS-Box Gene CUS1 Is Expressed during Cucumber Somatic Embryogenesis," Plant Science, Vol. 125, No. 1, 1997, pp. 63-74. doi:10.1016/S0168-9452(97)00056-3

[32] S.-K. Sung, G.-H. Yu, J. Nam, D.-H. Jeong and G. An, "Developmentally Regulated Expression of Two MADSBox Genes, MdMADS3 and MdMADS4, in the Morphogenesis of Flower Buds and Fruits in Apple," Planta, Vol. 210, No. 4, 2000, pp. 519-528.

[33] S.-K. Sung, G.-H. Yu and G. An, "Characterization of MdMADS2, a Member of the SQUAMOSA Subfamily of genes, in Apple," Plant Physiology, Vol. 120, No. 4, 1999, pp. 969-978. doi:10.1104/pp.120.4.969

[34] T. Foster, R. Johnston and A. Seleznyova, "A Morphological and Quantitative Characterization of Early Floral Development in Apple (Malus $\times$ domestica Borkh.)," Annals of Botany, Vol. 92, No. 2, 2003, pp. 199-206.

[35] S.-K. Sung and G. An, "Molecular Cloning and Characterization of a MADS-Box cDNA Clone of the Fuji Apple," Plant Cell Physiology, Vol. 38, No. 4, 1997, pp. 484-489.

[36] F. García-Maroto, M. J. Carmona, J. A. Garrido, M. Vilches-Ferrón, J. Rodríguez-Ruiz and D. López Alonso, "New Roles for MADS-Box Genes in Higher Plants," Biologia Plantarum, Vol. 46, No. 3, 2003, pp. 321-330.

[37] C. G. van der Linden, B. Vosman and M. J. M. Smulders, "Cell and Molecular Biology, Biochemistry and Molecular Physiology. Cloning and Characterization of Four Apple MADS Box Genes Isolated from Vegetative Tissue," Journal of Experimental Botany, Vol. 53, No. 371, 2002, pp. 1025-1036.

[38] T. Jack, "Plant Development Going MADS," Plant Molecular Biology, Vol. 46, No. 5, 2001, pp. 515-520. doi:10.1023/A:1010689126632

[39] S. Rounsley, G. Ditta and M. Yanofsky, "Diverse Roles for MADS Box Genes in Arabidopsis Development," The Plant Cell, Vol. 7, No. 8, 1995, pp. 1259-1269.

[40] H. Flachowsky, A. Peil, T. Sopanen, A. Elo and V. Hanke, "Overexpression of BpMADS4 from Silver Birch (Betula pendula Roth.) Induces Early-Flowering in Apple (Malus $\times$ domestica Borkh.)," Plant Breeding, Vol. 126, No. 2, 2007, pp. 137-145. doi:10.1111/j.1439-0523.2007.01344.x

[41] N. Kotoda and M. Wada, "MdTFL1, a TFL1-LIke Gene of Apple, Retards the Transition from the Vegetative to Reproductive Phase in Transgenic Arabidopsis," Plant Science, Vol. 168, No. 1, 2005, pp. 95-104. doi:10.1016/j.plantsci.2004.07.024

[42] V. Dal Cin, F. Rizzini, A. Botton and P. Tonutti, "The Ethylene Biosynthetic and Signal Transduction Pathways Are Differently Affected by 1-MCP in Apple and Peach Fruit," Postharvest Biology and Technology, Vol. 42, No. 2, 2006, pp. 125-133.

[43] H. Link, "Significance of Flower and Fruit Thinning on Fruit Quality," Plant Growth Regulation, Vol. 31, No. 1-2, 2000, pp. 17-26. doi:10.1023/A:1006334110068

[44] V. Dal Cin, G. Galla, A. Boschetti, A. Dorigoni, R. Velasco and A. Ramina, "Ethylene Involvement in Auxin Transport during Apple Fruitlet Abscission. (Malus $\times$ domestica L. Borkh.)," Advances in Plant Ethylene Research, Vol. 2, 2007, pp. 89-93.

[45] V. Dal Cin, G. Galla and A. Ramina, "MdACO Expression during Abscission. The Use of ${ }^{33} \mathrm{P}$ Labeled Primers in Transcript Quantitation," Molecular Biotechnology, Vol. 36, No. 1, 2007, pp. 9-13. doi:10.1007/s12033-007-0004-6

[46] V. Dal Cin, M. Danesin, F. Rizzini and A. Ramina, "RNA Extraction from Plant Tissues: The Use of Calcium to Precipitate Contaminating Pectic Sugars," Molecular Biotechnology, Vol. 31, No. 2, 2005 pp. 113-120. doi:10.1385/MB:31:2:113

[47] P. Nguyen and V. Dal Cin, "The Role of Light on Foliage Colour Development in Coleus (Solenostemon scutellariodes (L.) Codd)," Plant Physiology and Biochemistry, Vol. 47, No. 10, 2009, pp. 934-945.

[48] C. Schleiermacher, "GeneFisher-Software Support for the Detection of Postulated Genes," International Conference on Intelligent Systems for Molecular Biology, Vol. 4, 1996, pp. 68-77.

[49] S. Altschul, T. Madden, A. Schaffer, J. Zhang, Z. Zhang, W. Miller and D. Lipman, "Gapped BLAST and PSIBLAST: A New Generation of Protein Database Search Programs," Nucleic Acids Research, Vol. 25, No. 17, 1997, pp. 3389-3402. doi:10.1093/nar/25.17.3389

[50] K. Tamura, J. Dudley, M. Nei and S. Kumar, "MEGA4: Molecular Evolutionary Genetics Analysis (MEGA) Software Version 4.0," Molecular Biology and Evolution, Vol. 24, No. 8, 2007, pp. 1596-1599. doi:10.1093/molbev/msm092

[51] L. Parenicova, S. de Folter, M. Kieffer, D. S. Horner, C. Favalli, J. Busscher, H. E. Cook, R. M. Ingram, M. M. Kater, B. Davies, G. C. Angenent and L. Colombo, "Molecular and Phylogenetic Analyses of the Complete MADS-Box Transcription Factor Family in Arabidopsis: New Openings to the MADS World," The Plant Cell, Vol. 15, No. 7, 2003, pp. 1538-1551. doi:10.1105/tpc.011544

[52] L. C. Hileman, J. F. Sundstrom, A. Litt, M. Chen, T. Shumba and V. F. Irish, "Molecular and Phylogenetic Analyses of the MADS-Box Gene Family in Tomato," Molecular Biology and Evolution, Vol. 23, No. 11, 2006, pp. 2245-2258. doi:10.1093/molbev/msl095 
[53] J. Vrebalov, D. Ruezinsky, V. Padmanabhan, R. White, D. Medrano, R. Drake, W. Schuch and J. Giovannoni, "A MADS-Box Gene Necessary for Fruit Ripening at the Tomato Ripening-Inhibitor (Rin) Locus," Science, Vol. 296, No. 5566, 2002, pp. 343-346.

[54] E. Tani, A. N. Polidoros, E. Flemetakis, C. Stedel, C. Kalloniati, K. Demetriou, P. Katinakis and A. S. Tsaftaris, "Characterization and Expression Analysis of AGAMOUS-Like, SEEDSTICK-Like, and SEPALLATA-Like MADS-Box Genes in Peach (Prunus persica) Fruit," Plant Physiology and Biochemistry, Vol. 47, No. 8, 2009, pp. 690-700. doi:10.1016/i.plaphy.2009.03.013

[55] V. Cevik, C. Ryder, A. Popovich, K. Manning, G. King and G. Seymour, "A FRUITFULL-like Gene Is Associated with Genetic Variation for Fruit Flesh Firmness in Apple (Malus domestica Borkh.)," Tree Genetics \& Genomes, Vol. 6, No. 2, 2010, pp. 271-279. doi:10.1007/s11295-009-0247-4

[56] J. Vrebalov, I. L. Pan, A. Javier, M. Arroyo, R. McQuinn, M. Y. Chung, M. Poole, J. Rose, G. Seymour, S. Grandillo, J. Giovannoni and V. F. Irish, "Fleshy Fruit Expansion and Ripening Are Regulated by the Tomato SHATTERPROOF Gene TAGL1," The Plant Cell, Vol. 21, No. 10, 2009, pp. 3041-3062. doi:10.1105/tpc.109.066936

[57] J.-L. Yao, Y.-H Dong and B. A. M. Morris, "Parthenocarpic Apple Fruit Production Conferred by Transposon Insertion Mutations in a MADS-Box Transcription Factor," Proceedings of the National Academy of Sciences of the United States of America, Vol. 98, No. 3, 2001, pp. 1306-1311. doi:10.1073/pnas.031502498

[58] L. Mao, D. Begum, H.-W. Chuang, M. A. Budiman, E. J. Szymkowiak, E. E. Irish and R. A. Wing, "JOINTLESS Is a MADS-Box Gene Controlling Tomato Flower Abscission Zone Development," Nature, Vol. 406, 2000, pp. 910-913.

[59] Y. Huang, H. Li, C. E. Hutchison, J. Laskey and J. J. Kieber, "Biochemical and Functional Analysis of CTR1, a Protein Kinase That Negatively Regulates Ethylene Signaling in Arabidopsis," The Plant Journal, Vol. 33, No. 2, 2003, pp. 221-233. doi:10.1046/j.1365-313X.2003.01620.x

[60] L. Adams-Phillips, C. Barry, P. Kannan, J. Leclercq, M Bouzayen and J. Giovannoni, "Evidence That CTR1-Mediated Ethylene Signal Transduction in Tomato Is Encoded by a Multigene Family Whose Members Display Distinct Regulatory Features," Plant Molecular Biology, Vol. 54, No. 3, 2004, pp. 387-404. doi:10.1023/B:PLAN.0000036371.30528.26

[61] C. A. Frye, D. Z. Tang and R. W. Innes, "Negative Regulation of Defense Responses in Plants by a C. A. Conserved MAPKK Kinase," Proceedings of the National Academy of Sciences of the United States of America, Vol.
98, No. 1, 2001, pp. 373-378. doi:10.1073/pnas.011405198

[62] Z. Lin, L. Alexander, R. Hackett and D. Grierson, "LeCTR2, a CTR1-Like Protein Kinase from Tomato, Plays a Role in Ethylene Signalling, Development and Defence," The Plant Journal, Vol. 54, No. 6, 2008, pp. 1083-1093. doi:10.1111/j.1365-313X.2008.03481.X

[63] H.-L. Zhu, B.-Z. Zhu, Y. Shao, X.-G. Wang, X.-J. Lin, Y.-H. Xie, Y.-C. Li, H.-Y. Gao and Y. B. Luo, "Tomato Fruit Development and Ripening Are Altered by the Silencing of LeEIN2 Gene," Journal of Integrative Plant Biology, Vol. 48, No. 12, 2006, pp. 1478-1485. doi:10.1111/j.1744-7909.2006.00366.x

[64] D. Gallie and T. Young, "The Ethylene Biosynthetic and Perception Machinery Is Differentially Expressed during Endosperm and Embryo Development in Maize," Molecular Genetics and Genomics, Vol. 271, No. 3, 2004, pp. 267-281.

[65] V. Dal Cin, M. Danesin, A. Botton, A. Boschetti, A. Dorigoni and A. Ramina, "Ethylene and Preharvest Drop: The Effect of AVG and NAA on Fruit Abscission in Apple (Malus domestica L. Borkh)," Plant Growth Regulation, Vol. 56, No. 3, 2008 pp. 317-325. doi:10.1007/s10725-008-9312-5

[66] A. Botton, G. Eccher, C. Forcato, A. Ferrarini, M. Begheldo, M. Zermiani, S. Moscatello, A. Battistelli, R. Velasco, B. Ruperti and A. Ramina, "Signalling Pathways Mediating the Induction of Apple Fruitlet Abscission," Plant Physiology, Vol. 155, No. 1, pp. 185-208.

[67] E. Katz, P. Lagunes, J. Riov, D. Weiss and E. Goldschmidt, "Molecular and Physiological Evidence Suggests the Existence of a System II-Like Pathway of Ethylene Production in Non-Climacteric Citrus Fruit," Planta, Vol. 219, No. 2, 2004, pp. 243-252.

[68] S. T. Malcomber and E. A. Kellogg, "SEPALLATA Gene Diversification: Brave New Whorls," Trends in Plant Science, Vol. 10, No. 9, 2005, pp. 427-435. doi:10.1016/j.tplants.2005.07.008

[69] A. Mazzucato, I. Olimpieri, F. Siligato, M. E. Picarella and G. P. Soressi, "Characterization of Genes Controlling Stamen Identity and Development in a Parthenocarpic Tomato Mutant Indicates a Role for the DEFICIENS Ortholog in the Control of Fruit Set," Physiologia Plantarum, Vol. 132, No. 4, 2008, pp. 526-537. doi:10.1111/j.1399-3054.2007.01035.x

[70] C. Ampomah-Dwamena, B. A. Morris, P. Sutherland, B. Veit and J.-L. Yao, "Down-Regulation of $T M_{29}$, a Tomato SEPALLATA Homolog, Causes Parthenocarpic Fruit Development and Floral Reversion," Plant Physiology, Vol. 130, No. 2, 2002, pp. 605-617. 